\title{
Role of hypocretin in the medial preoptic area in the regulation of sleep, maternal behavior and body temperature of lactating rats.
}

\author{
Mayda Rivas ${ }^{1}$, Diego Serantes ${ }^{1}$, Florencia Peña ${ }^{1}$, Joaquín González ${ }^{1}$, Annabel Ferreira ${ }^{2}$, Pablo \\ Torterolo ${ }^{1}$, Luciana Benedetto ${ }^{1 *}$.
}

\author{
${ }^{1}$ Departamento de Fisiología, Facultad de Medicina, Universidad de la República, Montevideo, \\ Uruguay.
}

${ }^{2}$ Sección de Fisiología y Nutrición, Facultad de Ciencias, Universidad de la República, Montevideo, Uruguay.

\author{
*Please address correspondence to: \\ Dr. Luciana Benedetto
}

Departamento de Fisiología, Facultad de Medicina, Universidad de la República,

General Flores 2125, 11800 Montevideo, Uruguay.

TEL: + (598) 2924-3414 x 3232. E-mail: Ibenedet@fmed.edu.uy

\begin{abstract}
The hypocretins (HCRT), also known as orexin, includes two neuroexcitatory peptides, HCRT1 and HCRT-2 (orexin A y B, respectively), synthesized by neurons located in the postero-lateral hypothalamus, whose projections and receptors are widely distributed throughout the brain, including the medial preoptic area (mPOA). HCRT have been associated with a wide range of physiological functions including sleep-wake cycle, maternal behavior and body temperature, all regulated by the MPOA. Previously we showed that HCRT in the MPOA facilitates certain active maternal behaviors, while the blockade of HCRT-R1 increased the time spent in nursing. As mother rats mainly sleep while they nurse, we hypothesize that HCRT in the MPOA of lactating rats reduce sleep and nursing, while the intra-mPOA administration of the dual orexin receptor antagonist (DORA) would generate the opposite effect. Therefore, the aim of this study was to determine the role of HCRT within the MPOA, in the regulation and integration of the sleep-wake cycle, maternal behavior and body temperature of lactating rats. To evaluate this idea, we assessed the sleep-wake states, maternal behavior and body temperature of lactating rats following microinjections of HCRT-1 (100 and $200 \mu \mathrm{M})$ and DORA $(5 \mathrm{mM})$ into the mPOA. As expected, our data shows that HCRT-1 in mPOA promoted wakefulness and a slightly increase in body temperature, whereas DORA increased both NREM and REM sleep along with nursing and milk ejection. Taken together, our results strongly suggest that the reduction of the endogenous HCRT within the MPOA of lactating rats is important to promote sleep, nursing and milk ejection.
\end{abstract}


Keywords: hypocretin, orexin, hypothalamus, mPOA, sleep, nursing, maternal behavior.

\section{Introduction}

The hypocretinergic (HCRTergic) system has been associated with several physiological functions including the maintenance of wakefulness, the promotion of several motivated behaviors, such as maternal behavior, and the control of body temperature (Boutrel et al., 2010; D'Anna and Gammie, 2006; Harris et al., 2005; McGregor et al., 2011; Muschamp et al., 2007; Rivas et al., 2016; Torterolo et al., 2011; Yoshimichi et al., 2001). In this sense, the sleep disorder called narcolepsy, caused by the degeneration of the hypocretinergic neurons, is characterized by sleep attacks and cataplexy as well as the disruption of thermoregulation (Harding et al., 2019; van der Heide et al., 2016).

The hypocretins (HCRT), also known as orexins, consist of two neuroexcitatory peptides, HCRT1 and HCRT-2 (also called orexin A y B, respectively), synthesized by neurons located in the posterolateral hypothalamus, whose projections and receptors are widely distributed throughout the brain, including the medial preoptic area (mPOA) (Peyron et al., 1998; Sakurai et al., 1998; Taheri and Bloom, 2001; Trivedi et al., 1998). HCRT binds to two metabotropic receptors: HCRT type 1 (HCRT-R1) and type 2 receptors (HCRT-R2) with different affinity. HCRT receptors, HCRT-R1 in particular, are expressed in the mPOA (Marcus et al., 2001; Trivedi et al., 1998), a critical region for the regulation of several physiological functions, including sleep and wakefulness, body temperature (Kumar, 2004), as well as the maternal care of the pups (Numan, 1974; Numan and Stolzenberg, 2009; Stolzenberg and Numan, 2011).

There is a great experimental evidence, including studies using different methodological approaches, showing that the MPOA regulates the wake-sleep cycle. Specifically, lesions of the MPOA produced a reduction in non-REM (NREM) and REM sleep (John and Kumar, 1998; Lu et al., 2000; Srividya et al., 2006). In addition, administration of glutamate (Kaushik et al., 2011) or adenosine (Mendelson, 2000) into the MPOA, as well as the activation of GABAergic and galaninergic neurons of this area promote NREM sleep (Chung et al., 2017; Harding et al., 2018; Kroeger et al., 2018; Vanini et al., 2020). Recently, it has been reported that the chemogenetic activation of a group of glutamatergic neurons within the MPOA and surroundings areas increases wakefulness, and decreases both NREM and REM sleep (Mondino et al., 2021; Vanini et al., 2020), suggesting that mPOA contains not only sleep-inducing neurons, but also wake-promoting neurons.

Administration of HCRT-1 into the MPOA of male rats promotes wakefulness and reduces both NREM and REM sleep (Espana et al., 2001), but the effect in lactating rats is unknown. In this sense, there is a great body of evidence showing that the MPOA goes through several changes along the postpartum period (Fleming and Korsmit, 1996; Numan, 2006; Pereira and Morrell, 2009; Rondini et al., 2010; Uriarte et al., 2020). These changes may not only prepare the lactating female to the maternal care of the pups, but also alter the functionality of different circuits that allow to orchestrate maternal behavior with its own physiology. In recent reports, we explored how different neurotransmitters modifies sleep and maternal behavior acting through the MPOA of the lactating rat. Microinjection of the dopamine D2-receptor antagonist Raclopride into the MPOA reduces REM sleep, and its transitional stage from NREM sleep, while NREM sleep is not affected (Benedetto et al., 2017a). On the contrary, the $G_{A B A}$ antagonist Bicuculine has no effect on sleep while increases active maternal care of the pups (Benedetto et al., 2021). 
The mPOA also plays an important role in thermoregulation (Srividya et al., 2006). In fact, not only the neural mechanisms that regulates both sleep and body temperature seem to coexist anatomically within the MPOA but are also functionally linked (Cerri and Amici, 2021; Harding et al., 2018; Kumar, 2004). Regarding HCRT, it has been shown that the body temperature is increased by the administration of HCRT-1 into the third ventricle (Yoshimichi et al., 2001) and reduced by HCRT blockade (Martin et al., 2019; Rusyniak et al., 2011). However, its effect within the mPOA is unknown.

The MPOA has been largely known as a key neural site where the hormones and several neuromodulators act to mediate the maternal care of the pups (Benedetto et al., 2014; Rivas et al., 2016; Stolzenberg et al., 2019). Specifically, we have previously showed that HCRT in the mPOA facilitates certain active maternal behavior, while the blockade of HCRT-1 decreases active components of maternal behavior and promotes nursing (Rivas et al., 2016). Since mother rats mainly sleep while they are nursing (Benedetto et al., 2017b), the increased time spent in nursing found with HCRT blockade within the MPOA (Rivas et al., 2016), could be related to a sleep-promoting effect. Therefore, we hypothesize that HCRT administration into the MPOA of lactating rats reduces sleep and nursing, while the blocking of endogenous HCRT provokes the opposite effect. To assess this idea, this study aims to determine the effect of the microinjections of HCRT-1 and the dual orexin receptor antagonist (DORA) into the MPOA of lactating rats on sleep and wakefulness, maternal behavior and body temperature.

\section{Material and methods}

\section{Animals and housing}

Twenty-three primiparous Wistar female rats $(250 \mathrm{~g})$ and pups were used in this study. The experimental procedures were in strict accordance with the "Guide for the care and use of laboratory animals" (8th edition. National Academy Press, Washington D. C., 2011) and approved by the Institutional Animal Care Committee (expedient № 070153-000304). All efforts were made in order to minimize the number of animals and their suffering. We used the same conditions and experimental protocol described in previous articles (Benedetto et al., 2014; Benedetto et al., 2017a; Benedetto et al., 2017b). Animals were housed in a temperature-controlled $\left(22 \pm 1^{\circ} \mathrm{C}\right)$ room, under a 12 -h light/dark cycle (lights on at 6:00 a.m.), with ad libitum access to food and water. Two days before giving birth, pregnant females were housed individually. On postpartum day 1 (PPD1, birth $=$ day 0$)$, litters were culled to four female and four male pups per mother.

\section{Stereotaxic surgery}

Briefly, on PPD1 females were anesthetized with a mixture of ketamine/xylazine/acepromazine maleate $(80 / 2.8 / 2.0 \mathrm{mg} / \mathrm{kg}$. i.p.). Female rats were bilaterally implanted with 22-gauge stainless steel guide cannulae (Plastic One, Roanoke, VA) aimed $2 \mathrm{~mm}$ dorsal to the mPOA: AP $-0.5 \mathrm{~mm}$ (from Bregma); $\mathrm{ML} \pm 0.5 \mathrm{~mm}$ (from midline); $\mathrm{DV}-6.5 \mathrm{~mm}$ (from skull) according to (Paxinos and Watson, 2005). In addition, cortical electroencephalogram (EEG) and dorsal neck muscle electromyogram (EMG) electrodes were implanted for the assessment of sleep and wakefulness $(W)$ states. EEG electrodes were placed in the prefrontal cortex $(A P=+3.0 ; M L=2.0)$, parietal cortex $(\mathrm{AP}=-4.0, \mathrm{ML}=3.0)$, occipital cortex $(\mathrm{AP}=-7.0, \mathrm{ML}=3.0)$, and over the cerebellum as a reference electrode $(A P=-11.0, M L=0.0)$. Two additional stainless-steel screws were implanted into the skull as anchors. All electrodes were soldered to a six-pin connector. The connector and the guide cannulae were cemented to the skull using dental acrylic. Immediately after surgery, each mother was reunited with her pups in the home cage. 
At the end of the stereotaxic surgery, the lower dorsal part of the flank was shaved and a 1.5$2 \mathrm{~cm}$ long incision was made on the skin. A temperature data logger iButton (Thermochron, model DS2422) inside a silicone-coat capsule was implanted subcutaneously; thereafter, the skin was sutured. The iButton was implanted in the dorsal part of the animal to avoid interference with the mammary glands and suckling of the pups.

A pre-surgery single dose of ketoprofen $(5 \mathrm{mg} / \mathrm{kg}$, s.c.) was used to reduce pain. Also, topic antibiotic (Crema 6A, Labyes) was applied into the brain surgery injury and abdominal incision, and sterile $0.9 \%$ saline $(10 \mathrm{ml} / \mathrm{kg}$, s.c.) was administrated post-surgery to prevent dehydration during recovery (Benedetto et al., 2021).

\section{Experimental design}

All experiments were performed between PPD4-8 during the light phase. Before experiments began, a baseline recording session was performed to corroborate that all sleep parameters and maternal behaviors were adequate. Animals were randomly assigned to one of the following independent groups: HCRT or DORA group. For the HCRT group, each animal received a total of three microinjections: HCRT-1 $100 \mu \mathrm{M}$ (HCRT 100$),$ HCRT-1 $200 \mu \mathrm{M}$ (HCRT $\left.{ }_{200}\right)$ and sterile saline as vehicle. For DORA group, each animal received two microinjections: DORA $5 \mathrm{mM}$ and dimethyl sulfoxide (DMSO) as vehicle. All microinjections were administrated in a counterbalanced design and the day after the microinjections, no experiments were performed.

\section{Drugs}

HCRT-1 (BACHEM, Bubendorf, Switzerland) was diluted in sterile saline to obtain a final concentration of 100 and $200 \mu \mathrm{M}$. Aliquots for these doses were prepared in advance, frozen at -20 ${ }^{\circ} \mathrm{C}$, and thawed immediately before use. DORA TCS-1102 (Sigma-Aldrich, St Louis, USA) was diluted in DMSO $10 \%$ to obtain a final concentration of $5 \mathrm{mM}$. Similar doses were used in previous studies (Hsiao et al., 2012; Korim et al., 2014; Rivas et al., 2016).

\section{Microinjection procedure}

Microinjection procedure was performed using the injection cannulae (28 gauge; Plastic One, Roanoke, VA) extending $2 \mathrm{~mm}$ beyond the tip of the guide cannulae, and a constant-rate infusion pump (Harvard apparatus, USA). The rats were bilaterally microinjected with $0.2 \mu$ l of either HCRT-1, DORA, or the same volume of the correspondent vehicle into the mPOA over a period of $2 \mathrm{~min}$. The injection cannulae were left in place for an additional minute to allow for the diffusion of the drug. The same microinjection volume was used in previous studies of the group (Benedetto et al., 2014; Benedetto et al., 2017a; Benedetto et al., 2021; Rivas et al., 2016).

\section{Experimental sessions}

During each experimental day, at 9 a.m., pups were removed from the maternal cage for three hours and placed under a heat lamp. Fifteen minutes before the completion of maternal separation, microinjection procedure was performed. Thereafter, the rat was returned to her home cage and connected to the recording system. Then, the entire litter was weighed, and at the completion of the separation period the pups were scattered in the mothers' home cage opposite to the nest. Subsequently, polysomnographic recording and videotaping of the maternal behavior was initiated for four hours. After each recording session, the mother rat was disconnected from the recording device and the entire litter was weighed again. 


\section{Sleep recording}

Bioelectric signals were amplified $(\times 1000)$, filtered $(0.1-500 \mathrm{~Hz})$, sampled $(1024 \mathrm{~Hz}, 16$ bits) and stored in a PC for further analysis using the Spike 2 software. The states of light sleep (LS), slow wave sleep (SWS), REM sleep and W were determined in 5-s epochs with standard criteria (Benedetto et al., 2017a; Benedetto et al., 2017b; Benedetto et al., 2013). Additionally, the intermediate stage (IS, transition from NREM to REM sleep) was also distinguished (sleep spindles combined with theta activity) (Gottesmann, 1992). Total time spent in W, LS, SWS, NREM sleep (LS + SWS), IS and REM sleep over the total recording time and each hour separately were analyzed. In addition, sleep latencies (first episodes $\geq 20 \mathrm{~s}$ from the beginning of the recordings), number, and duration of episodes of each state were studied.

\section{EEG spectral power analysis}

EEG analysis of power $(1-45 \mathrm{~Hz})$ was conducted during the 4 hours after delivery of vehicle or drugs into mPOA. Spectrograms (time-frequency representation of the EEG signal) were examined in Spike 2. To further study the spectral characteristics, raw EEG signals from prefrontal and parietal channels were exported into MATLAB. The average power spectrum was obtained by means of the pwelch built-in MATLAB function (parameters: window $=1024$, noverlap $=[], \mathrm{fs}=1024, \mathrm{nfft}=1024$ ), which corresponds to 1-s sliding windows with half-window overlap, and a frequency resolution of 1 $\mathrm{Hz}$. All spectra were normalized to obtain the relative power by dividing the power value of each frequency by the sum across frequencies. Because notch filters $(50 \mathrm{~Hz})$ were applied to EEG channels in some recordings, we only considered the frequency bands up to $45 \mathrm{~Hz}$. For each animal in each treatment group, the mean power spectrum in each behavioral state (W, LS, SWS, IS, REM) was obtained by averaging the power spectra across all available windows in prefrontal and parietal cortices.

\section{Maternal behavior}

Maternal behavior was analyzed from digital videos and classified into three major categories: hovering over the pups (dam over the pups while actively engaged in any activity), nursing (low and high kyphosis and supine postures), and away from the pups. Maternal states were staged in 5-s epochs and analyzed for the 4-h-recording session taking each hour separately.

In addition, specific active maternal behaviors were measured: the number of retrievals of the pups into the nest and the latency to group the entire litter. Besides, the latency to the first nursing bout $\geq 2 \mathrm{~min}$, the number of milk ejections (indirectly through the stretching behavior of the pups (Lincoln et al., 1973; Voloschin and Tramezzani, 1979) and the percentage of the litter weight gain (as an indirect measurement of the amount of ejected milk (Benedetto et al., 2021; Lincoln et al., 1973; Peña et al., 2020; Stern, 1991) were recorded.

\section{Temperature recording}

The body temperature was automatically recorded by the iButtons. The onset of measurement was set to initiate 3 days post-surgery for a 5-day period, taking temperature readings every 3 minutes. The temperature resolution of the iButtons was $0.0625^{\circ} \mathrm{C}$. After the experiments were completed and the animals were sacrificed, the iButtons were removed and data acquired were downloaded to a PC.

\section{Histological verification of microinjection sites}


At the end of the experiment the animals were euthanized with an overdose of ketamine/xylazine, perfused with $4 \%$ paraformaldehyde, and their brains were removed for histological processing. Thereafter, the brains were cut in $100 \mu \mathrm{m}$ coronal sections with a vibratome. The location of mPOA microinjection sites were verified according to the neuroanatomical atlas of Paxinos and Watson (Paxinos and Watson, 2005).

\section{Statistics}

All values are presented as mean \pm S.E.M (standard error). Comparisons of sleep and maternal parameters among HCRT-1 groups were evaluated by one-way repeated measures (ANOVA) followed by Tukey post hoc test, while paired Student t-test was used to compare DORA groups. Differences in EEG power among groups were evaluated utilizing the Friedman test for the HCRT-1 group, and Wilcoxon signed-rank test for the DORA group, since the data did not show a normal distribution tested with the Lilliefors test. The criterion used to discard the null hypotheses was $p<0.05$.

\section{Results}

\section{Sites of injection}

As depicted in Figure 1, all microinjections included in the study were located within the mPOA between -0.12 and $-0.60 \mathrm{~mm}$ from Bregma, based on the examination of the cannulae tracks in the histological sections (Paxinos and Watson, 2005). In six animals the guide cannulae was located outside the mPOA and were excluded from the data analysis. Therefore, a total of 16 animals were included in the study. Figure 1 shows the microinjection sites of HCRT-1 and DORA groups.

\section{Effect of HCRT-1 on sleep and waking states}

Representative hypnograms and spectrograms (time-frequency representation of the EEG signal) from 0 to $30 \mathrm{~Hz}$ is shown for the HCRT group in Figure 2A. Sleep and waking parameters means are shown in Table 1 and Figures $2 \mathrm{~A}$ and 3 . Compared to vehicle, the total time spent in W significantly increased after the delivery of both $\mathrm{HCRT}_{100}$ and $\mathrm{HCRT}_{200}$. Furthermore, $\mathrm{HCRT}_{200}$ significantly decreased the total time spent in SWS, and there was a tendency to reduce the duration of the SWS episodes (Table 1 and Figures $2 \mathrm{~A}$ and 3 ).

Different REM sleep parameters were modified after HCRT. Specifically, the total time spent in REM was significantly reduced following $\mathrm{HCRT}_{200}$ microinjections. Also, the time spent in REM during the second hour was different among groups $(F(2,16)=11.11, p=0.001)$. Specifically, it was significantly reduced after local delivery of $\operatorname{HCRT}_{100}(p=0.023)$ and $\operatorname{HCRT}_{200}(p=0.001)$ compared to vehicle (see Figures $2 \mathrm{~A}$ and 3 ). Also, the number of REM episodes decreased and latency to REM increased after $\mathrm{HCRT}_{200}$ when compared to control values (Table 1).

As shown in Table 1 and Figure 3, no other sleep parameter differed among groups.

\section{Effect of DORA on sleep and waking states}

Representative hypnograms and spectrograms is shown for the DORA group in Figure 2B. The total time spent in $\mathrm{W}$, as well as the time spent in this state during the fourth recording hour $(t=2.75$, $p=0.016)$, were significantly reduced after microinjection of DORA into MPOA compared to vehicle (Table 2 and Figure 4). In addition, there was a significant reduction in the duration of $W$ episodes (Table 2). In concordance, DORA local delivery increased the total time spent in SWS as well as the time spent during the fourth recording hour $(t=2.62, \mathrm{p}=0.034$; Figures $2 \mathrm{~B}$ and 4$)$. 
Besides, the total time spent in REM increased after DORA microinjection, as well as the time in REM during the fourth recording hour ( $t=3.12, p=0.007$; Figures $2 B$ and 4$)$. Sleep parameters of LS and IS were not affected by DORA microinjection (Table 2 and Figure 4).

\section{EEG spectral analysis following administration of HCRT-1 and DORA}

An example spectrogram (time-frequency representation of the EEG signal) from 0 to $30 \mathrm{~Hz}$ for each experimental group is shown in Figure 4 and the mean power in Figure 5. Compared to vehicle, following HCRT-1 or DORA microinjections into the MPOA the EEG power did not differ in any frequency studied, neither in prefrontal, parietal cortex, W or sleep (Figure 5). We also extended the frequency bands studied up to $200 \mathrm{~Hz}$, but no differences were found (data not shown).

\section{Effect of HCRT-1 on maternal behavior}

Table 3 shows the results of HCRT-1 microinjection into MPOA on maternal behavior parameters. Only the litter weight gain decreased following HCRT 100 microinjection. HCRT-1 did not produce any additional significant changes in the maternal behaviors analyzed (Figure 6).

\section{Effect of DORA on maternal behavior}

Compared with vehicle administration, the local delivery of DORA into the MPOA produced an increase in the time that females spent nursing their pups. This enhancement was observed in the total recording time (Table 4) as well as during the fourth recording hour $(t=2.40, p=0.034$; Figure 6). In accordance, the number of milk ejections increased after microinjection of DORA compared to vehicle, and litter weight gain tended to increase (Table 4). Furthermore, DORA local delivery decreased the total time that dams spent away from the pups $(t=4.27, p=0.005$; Figure 6$)$, as well as during the fourth recording hour ( $t=4.81, p=0.003$; Figure 6$)$. There were no additional significant changes in other maternal behavior parameters analyzed (Table 4$)$.

\section{Effect of HCRT-1 and DORA on body temperature}

Compared to vehicle microinjections, body temperature differs among groups. Specifically, it increased after microinjection of $\mathrm{HCRT}_{200}$ during the first $\left(\mathrm{F}(2,14)=9.27, \mathrm{p}=0.004\right.$; Tukey: $\mathrm{HCRT}_{200}$ vs. saline $p=0.027$ ) and second hour $F(2,14)=6.83, p=0.010$; Tukey: $\mathrm{HCRT}_{200}$ vs. saline $p=0.017$ ) compared to control values (Figure 7).

DORA microinjection in the mPOA did not provoke significant changes in the body temperature of mother rats, neither in the total recording time nor during each hour analyzed separately (Figure 7).

\section{Discussion}

This study shows that local perfusion of HCRT-1 into MPOA of lactating rats increased total recording time spent awake and decreased time in both SWS and REM sleep, while the dual receptor antagonist of HCRT-receptors or DORA had the opposite effect. Together with the enhancement of sleep, local administration of DORA increased the time spent in nursing the pups and the number of milk ejections. These facts suggest that sleep and nursing, can be promoted together. In addition, while HCRT-1 microinjections increased body temperature, this parameter was not affected by DORA.

\section{Technical considerations}


We performed intracerebral microinjection of HCRT-1 and DORA in a volume of $0.2 \mu \mathrm{l}$, similarly to previous studies of our laboratory (Benedetto et al., 2014; Benedetto et al., 2017a; Benedetto et al., 2013 ; Lagos et al., 2009; Lagos et al., 2011; Rivas et al., 2016). Since the same volume of methylene blue has been shown to diffuse approximately $500 \mu \mathrm{m}$ in the CNS (Lohman et al., 2005), we cannot rule out the possibility that the drugs could have potentially affected limits of adjacent areas, as the lateral preoptic area, which are also a somnogenic areas.

\section{HCRT-1 microinjections into the MPOA modifies sleep but not EEG activity}

The fact that HCRT-1 infusion into the MPOA of lactating mother rats reduced sleep is consistent with previous evidence in male rats showing that microinjections of HCRT-1 in the preoptic area (POA) promotes $\mathrm{W}$, in spite that the target of the injection was more lateral than in the present study (Espana et al., 2001; Methippara et al., 2000). Taken together, we can hypothesize that HCRT-1 function on sleep is widespread along the POA and not restricted to the medial zone of the MPOA, and is consistent both in male and mother rats.

In accordance with HCRT-1 effects, our results show that local infusion of DORA decreased total time spent awake while increased the time in SWS and REM sleep. These data strongly suggest that there is a tonic endogenous release of HCRT in MPOA sleeping circuits. It is important to note, that the DORA Suvorexant has been approved in 2014 as a hypnotic drug by the Food Drug Administration (FDA) (Yang, 2014). Nevertheless, to the best of our knowledge, its effect during the postpartum period has not been studied before, neither in humans nor in animal models.

The $\mathrm{mPOA}$ is a heterogeneous region composed of cells that release several neurotransmitters, such as GABA, glutamate, dopamine, and several neuropeptides (Simerly et al., 1986; Tsuneoka et al., 2013). Although most of the neurons whose activity have been related to sleep are GABAergic (Fang et al., 2018; Lonstein and De Vries, 2000; Tsuneoka et al., 2013), it has been recently showed that a subgroup of glutamatergic neurons within the MPOA promotes NREM sleep together with body cooling (Harding et al., 2018). In addition to somnogenic POA neurons, it has been recently reported a group of glutamatergic neurons within the MPOA whose chemogenetic activation increases wakefulness, and decreases both NREM and REM sleep (Mondino et al., 2021; Vanini et al., 2020). Regarding the mechanisms underlying the effects of HCRT in POA neurons, (Eggermann et al., 2001) have studied the effects of HCRT-1 perfusion in neurons of VLPO in rat brain slices. Specifically, they show that HCRT have no effects on the GABA sleep-promoting neurons of the ventrolateral preoptic area (VLPO), whereas they have a strong and direct excitatory effect on the cholinergic neurons of the adjacent basal forebrain, and this effect was dependent on the activation of the HCRTR2. Moreover, in median preoptic nucleus (MnPO) neurons, through patch-clamp recording in rat brain slices, (Kolaj et al., 2008) have shown that HCRT applications induced a direct postsynaptic depolarization and excitation of glutamatergic currents but had no influence on GABAergic currents. Although sleep active and sleep promoting neurons of the POA are present mainly in the VLPO and MnPO (Gong et al., 2004; Kroeger et al., 2018; Sherin et al., 1996; Szymusiak et al., 1998; Vanini et al., 2020), somnogenic neurons are also present in mPOA (Chung et al., 2017; Harding et al., 2018). However, there are no previous reports exploring the effect of HCRT in MPOA neurons. Although the present study does not provide information about the specific neurons that were affected by HCRT-1 to produce the observed effects, given previous evidence we can speculate that HCRT-1 local administration into the MPOA could be acting directly into glutamatergic rather than in GABAergic neurons.

Even though HCRT-1 and DORA in MPOA affected sleep-wake times, these changes were not accompanied with EEG power modifications in any frequency or behavioral stage studied. This is in 
accordance with (Hungs and Mignot, 2001), who showed that HCRT neuron ablation in mice not affected the EEG power spectrum in any state. However, intracerebroventricular HCRT-1 administration in male rats decreased delta and alpha power, and theta and beta power increased (Toth et al., 2012); while a low dose of HCRT-1 (140 pmol) only decreased delta power but had no changes in theta-potency (Magdaleno-Madrigal et al., 2019). Collectively, these data suggest that HCRT-1 effects on EEG power are dependent on other brain areas rather than the MPOA. Interestingly, in humans, EEG power spectra in non-REM sleep was not affected by the hypnotic DORA SB-649868 (Bettica et al., 2012); while Suvorexant at clinically effective doses has limited effects on power spectral density, suggesting that the antagonism of the HCRT pathway might lead to improvements in sleep without major changes in the patient's EEG profile (Ma et al., 2014).

\section{HCRT into the MPOA modifies maternal behavior}

Our results show that the blockade of the action of endogenous HCRT intra-mPOA by DORA increased the time that mother rats spent nursing and the number of milk ejections. The increase in nursing occurred at the expense of a decrease in the time that dams spent away from the pups without affecting the time in hovering over the pups, indicating that DORA increased the time that mothers spent with the pups. This is in accordance with (Grieb et al., 2018), who showed that the endogenous levels of HCRT-1 within the MPOA are negatively correlated with the frequency of contact with the litter and kyphosis postures. However, hover over the pups was negatively correlated with the high levels of HCRT-1. These results together suggest that natural differences in endogenous HCRT levels within the MPOA may lead to maternal behavior differences among individuals.

In contrast, most maternal behaviors analyzed in the present report were undisturbed by the administration of HCRT-1 into mPOA. Only HCRT 100 reduced litter weight gain, but without affecting nursing time. This is consistent with our previous study, in which latencies and durations of nursing behaviors did not differ after microinjections of HCRT-1 10 and $100 \mu \mathrm{M}$, measured in a 30-minute maternal test (Rivas et al., 2016). Together, this lack of effect of HCRT-1 administration on maternal behaviors suggests that the endogenous HCRT tonic levels in MPOA might be already high. Hence, HCRT-1 administered exogenously had no additional effect in the modulation of maternal behavior.

Recently, Diniz et al. (2018) showed a greater number of HCRT-immunoreactive neurons in lactating dams compared to that of virgin females, and a decrease from PPD15 to PPD21 in response to regular suckling stimulus of pups, suggesting that a role of HCRTergic system during the lactation period (Diniz et al., 2018). However, the specific role that HCRT play in maternal behavior remains to be elucidated.

\section{HCRT, MPOA and thermoregulation}

The higher dose of HCRT-1 ( $\left.\mathrm{HCRT}_{200}\right)$ increased body temperature during the first and second hour after its microinjection into mPOA. This is in accordance with elevated body temperature after infusion of HCRT-1 intracerebroventricular in rats, with a peak at about 3 hours (Yoshimichi et al., 2001). Regarding the POA, only one study has administered HCRT-1 (1mM) into lateral preoptic area of male rats, but brain temperature was not affected by HCRT-1 (Methippara et al., 2000). These data, together with the present results, suggest that the HCRT modulates body temperature acting specifically within the MPOA rather than in other POA areas, supporting the large body of evidence that establish the MPOA as a key center of body temperature regulation (Boulant, 2000; Harding et al., 2018; Morrison, 2016). However, blocking endogenous HCRT action by the administration of DORA had no effect on body temperature of the mothers. This latter result could suggest that endogenous HCRT may not be playing a main role in maintaining basal temperature throughout the MPOA circuit 
in lactating dams, which could reflect the changes in the MPOA circuits during motherhood and lactation. In this sense, it is important to note that functional differences in MPOA networks have been reported between male and postpartum female rats (Bleier et al., 1982; Brown et al., 1988; Gorski et al., 1978; Ottem et al., 2004; Raisman and Field, 1971).

In the present report, the increase in maternal body temperature provoked by $\mathrm{HCRT}_{200}$ was not accompanied by changes in the time spent in nursing. Although (Leon et al., 1978) suggest that nursing bouts are limited by a rise in maternal temperature, and that the rate of temperature rise determines the duration of each bout, other evidence show that hyperthermic mothers (following treatment with morphine plus naloxone) nurse their litter normally. These results suggest that nursing bouts in lactating rats are not limited by the mother's temperature (Stern and Azzara, 2002). Thus, body temperature and nursing integration are still to be determined.

\section{Conclusions}

Our work shows that in lactating rats, HCRT-1 modulates MPOA to promote wakefulness, whereas DORA promotes both NREM and REM sleep. These effects of DORA on sleep parameters are accompanied by an increase in the time that mother rats nurse their litter and in the number of milk ejections. HCRT-1 into mPOA promoted wakefulness that was associated with a slight increase in body temperature, whereas DORA did not alter body temperature in lactating mother rats. Taken together, our results suggest that the reduction of the endogenous HCRT within the MPOA of lactating rats is important to promote sleep, nursing and milk ejection simultaneously, without affecting body temperature, while external additional HCRT mainly promotes wakefulness and increase body temperature in this behavioral state. Overall, this study highlights the role of the hypocretinergic system, by acting through mPOA neurons, in the modulation of sleep, maternal behavior and body temperature in an integrated fashion.

\section{Acknowledgements}

This work was partially supported by "Programa de Desarrollo de Ciencias Básicas (PEDECIBA)" and "Agencia Nacional de Investigación e Innovación (ANII)". All authors have seen and approved the manuscript, and it hasn't been accepted or published elsewhere. The authors have no competing interests.

\section{References}

Benedetto L, Pereira M, Ferreira A, Torterolo P (2014), Melanin-concentrating hormone in the medial preoptic area reduces active components of maternal behavior in rats. Peptides 58C:20-25.

Benedetto L, Rivas M, Cavelli M, Pena F, Monti J, Ferreira A, Torterolo P (2017a), Microinjection of the dopamine D2-receptor antagonist Raclopride into the medial preoptic area reduces REM sleep in lactating rats. Neuroscience letters 659:104-109.

Benedetto L, Rivas M, Peña F, Serantes D, Ferreira A, Torterolo P, Local administration of bicuculline into the ventrolateral and medial preoptic nuclei modifies sleep and maternal behavior in lactating rats, 2021.

Benedetto L, Rivas M, Pereira M, Ferreira A, Torterolo P (2017b), A descriptive analysis of sleep and wakefulness states during maternal behaviors in postpartum rats. Arch Ital Biol 155:99-109.

Benedetto L, Rodriguez-Servetti Z, Lagos P, D'Almeida V, Monti JM, Torterolo P (2013), Microinjection of melanin concentrating hormone into the lateral preoptic area promotes non-REM sleep in the rat. Peptides 39:11-15. 
Bettica P, Squassante L, Groeger JA, Gennery B, Winsky-Sommerer R, Dijk DJ (2012), Differential effects of a dual orexin receptor antagonist (SB-649868) and zolpidem on sleep initiation and consolidation, SWS, REM sleep, and EEG power spectra in a model of situational insomnia. Neuropsychopharmacology 37:1224-1233.

Bleier R, Byne W, Siggelkow I (1982), Cytoarchitectonic sexual dimorphisms of the medial preoptic and anterior hypothalamic areas in guinea pig, rat, hamster, and mouse. The Journal of comparative neurology 212:118-130.

Boulant JA (2000), Role of the preoptic-anterior hypothalamus in thermoregulation and fever. Clin Infect Dis 31 Suppl 5:S157-161.

Boutrel B, Cannella N, de Lecea L (2010), The role of hypocretin in driving arousal and goal-oriented behaviors. Brain research 1314:103-111.

Brown TJ, Hochberg RB, Zielinski JE, MacLusky NJ (1988), Regional sex differences in cell nuclear estrogen-binding capacity in the rat hypothalamus and preoptic area. Endocrinology 123:1761-1770.

Cerri M, Amici R (2021), Thermoregulation and Sleep: Functional Interaction and Central Nervous Control. Comprehensive Physiology 11:1591-1604.

Chung S, Weber F, Zhong P, Tan CL, Nguyen TN, Beier KT, Hormann N, Chang WC, et al. (2017), Identification of preoptic sleep neurons using retrograde labelling and gene profiling. Nature 545:477481.

D'Anna KL, Gammie SC (2006), Hypocretin-1 dose-dependently modulates maternal behaviour in mice. Journal of neuroendocrinology 18:553-566.

Diniz GB, Candido PL, Klein MO, Alvisi RD, Presse F, Nahon JL, Felicio LF, Bittencourt JC (2018), The weaning period promotes alterations in the orexin neuronal population of rats in a suckling-dependent manner. Brain structure \& function 223:3739-3755.

Eggermann E, Serafin M, Bayer L, Machard D, Saint-Mleux B, Jones BE, Muhlethaler M (2001), Orexins/hypocretins excite basal forebrain cholinergic neurones. Neuroscience 108:177-181.

Espana RA, Baldo BA, Kelley AE, Berridge CW (2001), Wake-promoting and sleep-suppressing actions of hypocretin (orexin): basal forebrain sites of action. Neuroscience 106:699-715.

Fang YY, Yamaguchi T, Song SC, Tritsch NX, Lin D (2018), A Hypothalamic Midbrain Pathway Essential for Driving Maternal Behaviors. Neuron 98:192-207 e110.

Fleming AS, Korsmit M (1996), Plasticity in the maternal circuit: effects of maternal experience on FosLir in hypothalamic, limbic, and cortical structures in the postpartum rat. Behav Neurosci 110:567-582. Gong H, McGinty D, Guzman-Marin R, Chew KT, Stewart D, Szymusiak R (2004), Activation of c-fos in GABAergic neurones in the preoptic area during sleep and in response to sleep deprivation. The Journal of physiology 556:935-946.

Gorski RA, Gordon JH, Shryne JE, Southam AM (1978), Evidence for a morphological sex difference within the medial preoptic area of the rat brain. Brain research 148:333-346.

Gottesmann C (1992), Detection of seven sleep-waking stages in the rat. Neurosci Biobehav Rev 16:3138.

Grieb ZA, Holschbach MA, Lonstein JS (2018), Interaction between postpartum stage and litter age on maternal caregiving and medial preoptic area orexin. Physiology \& behavior 194:430-436.

Harding EC, Franks NP, Wisden W (2019), The Temperature Dependence of Sleep. Frontiers in neuroscience 13:336.

Harding EC, Yu X, Miao A, Andrews N, Ma Y, Ye Z, Lignos L, Miracca G, et al. (2018), A Neuronal Hub Binding Sleep Initiation and Body Cooling in Response to a Warm External Stimulus. Curr Biol 28:22632273 e2264.

Harris GC, Wimmer M, Aston-Jones G (2005), A role for lateral hypothalamic orexin neurons in reward seeking. Nature 437:556-559.

Hsiao YT, Jou SB, Yi PL, Chang FC (2012), Activation of GABAergic pathway by hypocretin in the median raphe nucleus (MRN) mediates stress-induced theta rhythm in rats. Behavioural brain research 233:224-231.

Hungs M, Mignot E (2001), Hypocretin/orexin, sleep and narcolepsy. Bioessays 23:397-408. 
John J, Kumar VM (1998), Effect of NMDA lesion of the medial preoptic neurons on sleep and other functions. Sleep 21:587-598.

Kaushik MK, Kumar VM, Mallick HN (2011), Glutamate microinjection at the medial preoptic area enhances slow wave sleep in rats. Behavioural brain research 217:240-243.

Kolaj M, Coderre E, Renaud LP (2008), Orexin peptides enhance median preoptic nucleus neuronal excitability via postsynaptic membrane depolarization and enhancement of glutamatergic afferents. Neuroscience 155:1212-1220.

Korim WS, Bou Farah L, McMullan S, Verberne AJ (2014), Orexinergic activation of medullary premotor neurons modulates the adrenal sympathoexcitation to hypothalamic glucoprivation. Diabetes 63:1895-1906.

Kroeger D, Absi G, Gagliardi C, Bandaru SS, Madara JC, Ferrari LL, Arrigoni E, Munzberg H, et al. (2018), Galanin neurons in the ventrolateral preoptic area promote sleep and heat loss in mice. Nature communications 9:4129.

Kumar VM (2004), Why the medial preoptic area is important for sleep regulation. Indian J Physiol Pharmacol 48:137-149.

Lagos P, Torterolo P, Jantos H, Chase MH, Monti JM (2009), Effects on sleep of melanin-concentrating hormone $(\mathrm{MCH})$ microinjections into the dorsal raphe nucleus. Brain research 1265:103-110.

Lagos P, Torterolo P, Jantos H, Monti JM (2011), Immunoneutralization of melanin-concentrating hormone $(\mathrm{MCH})$ in the dorsal raphe nucleus: effects on sleep and wakefulness. Brain research 1369:112-118.

Leon M, Croskerry PG, Smith GK (1978), Thermal control of mother-young contact in rats. Physiology \& behavior 21:790-811.

Lincoln DW, Hill A, Wakerley JB (1973), The milk-ejection reflex of the rat: an intermittent function not abolished by surgical levels of anaesthesia. J Endocrinol 57:459-476.

Lohman RJ, Liu L, Morris M, O'Brien TJ (2005), Validation of a method for localised microinjection of drugs into thalamic subregions in rats for epilepsy pharmacological studies. J Neurosci Methods 146:191-197.

Lonstein JS, De Vries GJ (2000), Maternal behaviour in lactating rats stimulates c-fos in glutamate decarboxylase-synthesizing neurons of the medial preoptic area, ventral bed nucleus of the stria terminalis, and ventrocaudal periaqueductal gray. Neuroscience 100:557-568.

Lu J, Greco MA, Shiromani P, Saper CB (2000), Effect of lesions of the ventrolateral preoptic nucleus on NREM and REM sleep. J Neurosci 20:3830-3842.

Ma J, Svetnik V, Snyder E, Lines C, Roth T, Herring WJ (2014), Electroencephalographic power spectral density profile of the orexin receptor antagonist suvorexant in patients with primary insomnia and healthy subjects. Sleep 37:1609-1619.

Magdaleno-Madrigal VM, Morales-Mulia S, Nicolini H, Genis-Mendoza A, Cazares-Martinez Claudia E, Perez-Luna Jose M, Morales-Mulia M (2019), Orexin-A promotes EEG changes but fails to induce anxiety in rats. Behavioural brain research 361:26-31.

Marcus JN, Aschkenasi CJ, Lee CE, Chemelli RM, Saper CB, Yanagisawa M, Elmquist JK (2001), Differential expression of orexin receptors 1 and 2 in the rat brain. The Journal of comparative neurology 435:6-25.

Martin T, Dauvilliers Y, Koumar OC, Besnard S, Dauphin F, Bessot N (2019), Dual orexin receptor antagonist induces changes in core body temperature in rats after exercise. Scientific reports 9:18432.

McGregor R, Wu MF, Barber G, Ramanathan L, Siegel JM (2011), Highly specific role of hypocretin (orexin) neurons: differential activation as a function of diurnal phase, operant reinforcement versus operant avoidance and light level. J Neurosci 31:15455-15467.

Mendelson WB (2000), Sleep-inducing effects of adenosine microinjections into the medial preoptic area are blocked by flumazenil. Brain research 852:479-481.

Methippara MM, Alam MN, Szymusiak R, McGinty D (2000), Effects of lateral preoptic area application of orexin-A on sleep-wakefulness. Neuroreport 11:3423-3426. 
Mondino A, Hambrecht-Wiedbusch V, Li D, York AK, Pal D, Gonzalez J, Torterolo P, Mashour GA, et al. (2021), Glutamatergic neurons in the preoptic hypothalamus promote wakefulness, destabilize NREM sleep, suppress REM sleep, and regulate cortical dynamics. J Neurosci.

Morrison SF (2016), Central control of body temperature. F1000Research 5.

Muschamp JW, Dominguez JM, Sato SM, Shen RY, Hull EM (2007), A role for hypocretin (orexin) in male sexual behavior. J Neurosci 27:2837-2845.

Numan M (1974), Medial preoptic area and maternal behavior in the female rat. J Comp Physiol Psychol 87:746-759.

Numan M (2006), Hypothalamic neural circuits regulating maternal responsiveness toward infants. Behav Cogn Neurosci Rev 5:163-190.

Numan M, Stolzenberg DS (2009), Medial preoptic area interactions with dopamine neural systems in the control of the onset and maintenance of maternal behavior in rats. Front Neuroendocrinol 30:4664.

Ottem EN, Godwin JG, Krishnan S, Petersen SL (2004), Dual-phenotype GABA/glutamate neurons in adult preoptic area: sexual dimorphism and function. J Neurosci 24:8097-8105.

Paxinos G, Watson C (2005) The Rat Brain in Stereotaxic Coordinates. San Diego, California: Elsevier Academic Press.

Peña F, Rivas M, Gonzalez J, Schwarzkopf N, Torterolo P, Ferreira A, Benedetto L (2020), Sleep and maternal behavior in the postpartum rat after haloperidol and midazolam treatments. Sleep Science 13 78-86.

Pereira M, Morrell Jl (2009), The changing role of the medial preoptic area in the regulation of maternal behavior across the postpartum period: facilitation followed by inhibition. Behavioural brain research 205:238-248.

Peyron C, Tighe DK, van den Pol AN, de Lecea L, Heller HC, Sutcliffe JG, Kilduff TS (1998), Neurons containing hypocretin (orexin) project to multiple neuronal systems. J Neurosci 18:9996-10015.

Raisman G, Field PM (1971), Sexual dimorphism in the preoptic area of the rat. Science (New York, NY 173:731-733.

Rivas $M$, Torterolo P, Ferreira A, Benedetto L (2016), Hypocretinergic system in the medial preoptic area promotes maternal behavior in lactating rats. Peptides 81:9-14.

Rondini TA, Donato J, Jr., Rodrigues Bde C, Bittencourt JC, Elias CF (2010), Chemical identity and connections of medial preoptic area neurons expressing melanin-concentrating hormone during lactation. J Chem Neuroanat 39:51-62.

Rusyniak DE, Zaretsky DV, Zaretskaia MV, DiMicco JA (2011), The role of orexin-1 receptors in physiologic responses evoked by microinjection of PgE2 or muscimol into the medial preoptic area. Neurosci Lett 498:162-166.

Sakurai T, Amemiya A, Ishii M, Matsuzaki I, Chemelli RM, Tanaka H, Williams SC, Richarson JA, et al. (1998), Orexins and orexin receptors: a family of hypothalamic neuropeptides and $G$ protein-coupled receptors that regulate feeding behavior. Cell 92:1 page following 696.

Sherin JE, Shiromani PJ, McCarley RW, Saper CB (1996), Activation of ventrolateral preoptic neurons during sleep. Science (New York, NY 271:216-219.

Simerly RB, Gorski RA, Swanson LW (1986), Neurotransmitter specificity of cells and fibers in the medial preoptic nucleus: an immunohistochemical study in the rat. The Journal of comparative neurology 246:343-363.

Srividya R, Mallick HN, Kumar VM (2006), Differences in the effects of medial and lateral preoptic lesions on thermoregulation and sleep in rats. Neuroscience 139:853-864.

Stern JM (1991), Nursing posture is elicited rapidly in maternally naive, haloperidol-treated female and male rats in response to ventral trunk stimulation from active pups. Horm Behav 25:504-517.

Stern JM, Azzara AV (2002), Thermal control of mother-young contact revisited: hyperthermic rats nurse normally. Physiol Behav 77:11-18. 
Stolzenberg D, Hernandez-D'Anna K, Bosch O, Lonstein J (2019) Maternal behavior from a neuroendocrine perspective. In: Oxford Research Encyclopedia of Neuroscience, vol. (Stolzenberg DS, Hernandez-D'Anna KL, Bosch OJ, JS. L, eds). Oxford, UK: Oxford University Press.

Stolzenberg DS, Numan M (2011), Hypothalamic interaction with the mesolimbic DA system in the control of the maternal and sexual behaviors in rats. Neurosci Biobehav Rev 35:826-847.

Szymusiak R, Alam N, Steininger TL, McGinty D (1998), Sleep-waking discharge patterns of ventrolateral preoptic/anterior hypothalamic neurons in rats. Brain research 803:178-188.

Taheri S, Bloom S (2001), Orexins/hypocretins: waking up the scientific world. Clinical endocrinology 54:421-429.

Torterolo P, Ramos OV, Sampogna S, Chase MH (2011), Hypocretinergic neurons are activated in conjunction with goal-oriented survival-related motor behaviors. Physiology \& behavior 104:823-830. Toth A, Balatoni B, Hajnik T, Detari L (2012), EEG effect of orexin A in freely moving rats. Acta physiologica Hungarica 99:332-343.

Trivedi P, Yu H, MacNeil DJ, Van der Ploeg LH, Guan XM (1998), Distribution of orexin receptor mRNA in the rat brain. FEBS Lett 438:71-75.

Tsuneoka Y, Maruyama T, Yoshida S, Nishimori K, Kato T, Numan M, Kuroda KO (2013), Functional, anatomical, and neurochemical differentiation of medial preoptic area subregions in relation to maternal behavior in the mouse. The Journal of comparative neurology 521:1633-1663.

Uriarte N, Ferreno M, Mendez D, Nogueira J (2020), Reorganization of perineuronal nets in the medial Preoptic Area during the reproductive cycle in female rats. Scientific reports 10:5479.

van der Heide A, Hegeman-Kleinn IM, Peeters E, Lammers GJ, Fronczek R (2016), Immunohistochemical screening for antibodies in recent onset type 1 narcolepsy and after H1N1 vaccination. Journal of neuroimmunology 283:58-62.

Vanini G, Bassana M, Mast M, Mondino A, Cerda I, Phyle M, Chen V, Colmenero AV, et al. (2020), Activation of Preoptic GABAergic or Glutamatergic Neurons Modulates Sleep-Wake Architecture, but Not Anesthetic State Transitions. Curr Biol 30:779-787 e774.

Voloschin LM, Tramezzani JH (1979), Milk ejection reflex linked to slow wave sleep in nursing rats. Endocrinology 105:1202-1207.

Yang LP (2014), Suvorexant: first global approval. Drugs 74:1817-1822.

Yoshimichi G, Yoshimatsu H, Masaki T, Sakata T (2001), Orexin-A regulates body temperature in coordination with arousal status. Experimental biology and medicine (Maywood, NJ 226:468-476. 
bioRxiv preprint doi: https://doi.org/10.1101/2021 05.06.442961; this version posted May 7, 2021. The copyright holder for this preprint (which was not certified by peer review) is the author/funder, who has granted bioRxiv a license to display the preprint in perpetuity. It is made available under aCC-BY-NC-ND 4.0 International license.

Table 1. Effects of microinjection of HCRT-1 into mPOA on sleep parameters during 4-hour sessions.

\begin{tabular}{|c|c|c|c|c|c|c|}
\hline & \multirow[t]{2}{*}{ Vehicle } & \multirow[t]{2}{*}{ HCRT $_{100}$} & \multirow[t]{2}{*}{ HCRT $_{200}$} & \multicolumn{2}{|c|}{ ANOVA } & \multirow{2}{*}{$\begin{array}{c}\text { Tukey } \\
\mathrm{P}\end{array}$} \\
\hline & & & & $\mathrm{F}$ & $P$ & \\
\hline \multicolumn{7}{|l|}{ Wakefulness } \\
\hline Total duration (min) & $105.29 \pm 8.01$ & $117.43 \pm 6.06^{*}$ & $120.74 \pm 6.15^{*}$ & 7.64 & 0.005 & $\begin{array}{l}0.001 \\
0.003\end{array}$ \\
\hline Number of episodes & $133.44 \pm 8.32$ & $145.33 \pm 8.74$ & $155.56 \pm 12.40$ & 1.51 & 0.250 & \\
\hline Episodes duration (min) & $0.81 \pm 0.09$ & $0.83 \pm 0.08$ & $0.80 \pm 0.08$ & 0.09 & 0.911 & \\
\hline \multicolumn{7}{|l|}{ Light Sleep } \\
\hline Total duration (min) & $32.19 \pm 2.62$ & $32.00 \pm 2.55$ & $34.04 \pm 2.94$ & 0.31 & 0.737 & \\
\hline Number of episodes & $186.44 \pm 12.64$ & $197.44 \pm 14.87$ & $209.56 \pm 19.34$ & 1.28 & 0.305 & \\
\hline Episodes duration (min) & $0.17 \pm 0.01$ & $0.16 \pm 0.01$ & $0.16 \pm 0.01$ & 0.93 & 0.414 & \\
\hline \multicolumn{7}{|l|}{ Slow Wave Sleep } \\
\hline Total duration (min) & $83.17 \pm 4.78$ & $73.20 \pm 5.28$ & $73.03 \pm 4.69^{*}$ & 4.41 & 0.030 & 0.049 \\
\hline Number of episodes & $133.78 \pm 9.61$ & $139.11 \pm 11.22$ & $143.78 \pm 13.33$ & 0.63 & 0.544 & \\
\hline Episodes duration (min) & $0.63 \pm 0.03$ & $0.54 \pm 0.06$ & $0.52 \pm 0.05$ & 3.91 & 0.041 & 0.051 \\
\hline \multicolumn{7}{|l|}{ Intermediate stage } \\
\hline Total duration (min) & $5.22 \pm 1.34$ & $6.39 \pm 1.15$ & $4.66 \pm 1.29$ & 0.85 & 0.445 & \\
\hline Number of episodes & $16.33 \pm 2.99$ & $19.33 \pm 3.02$ & $12.67 \pm 3.40$ & 2.87 & 0.086 & \\
\hline Episodes duration (min) & $0.30 \pm 0.05$ & $0.32 \pm 0.05$ & $0.31 \pm 0.06$ & 0.09 & 0.915 & \\
\hline \multicolumn{7}{|l|}{ REM Sleep } \\
\hline Total duration (min) & $14.13 \pm 2.09$ & $10.98 \pm 1.71$ & $7.54 \pm 1.54^{*}$ & 10.04 & 0.001 & 0.001 \\
\hline Number of episodes & $12.44 \pm 2.00$ & $9.89 \pm 1.48$ & $6.33 \pm 1.73^{*}$ & 8.67 & 0.003 & 0.002 \\
\hline Episodes duration (min) & $1.23 \pm 0.23$ & $1.18 \pm 0.20$ & $1.21 \pm 0.31$ & 0.04 & 0.964 & \\
\hline Latency NREM (min) & $13.13 \pm 2.29$ & $13.25 \pm 4.10$ & $18.90 \pm 3.82$ & 1.81 & 0.195 & \\
\hline Latency REM (min) & $81.41 \pm 11.88$ & $91.90 \pm 11.05$ & $136.94 \pm 19.90 *$ & 7.26 & 0.006 & 0.007 \\
\hline
\end{tabular}

Data is presented as mean \pm standard error of nine rats. ${ }^{*}$ denote significant difference compared to control values, using one-way repeated measures ANOVA followed by Tukey test.

Table 2. Effects of microinjection of DORA into MPOA on sleep parameters during 4-hour sessions.

\begin{tabular}{lcccc}
\hline & DMSO & DORA & t & P \\
\hline Wakefulness & & & & \\
Total duration (min) & $131.61 \pm 5.63$ & $115.88 \pm 3.08^{*}$ & 3.10 & 0.017 \\
Number of episodes & $109.25 \pm 12.19$ & $127.88 \pm 10.30$ & 2.16 & 0.068 \\
Episodes duration (min) & $1.32 \pm 0.18$ & $0.95 \pm 0.08^{*}$ & 2.61 & 0.035 \\
Light Sleep & & & & \\
Total duration (min) & $27.75 \pm 3.80$ & $28.54 \pm 3.06$ & 0.34 & 0.743 \\
Number of episodes & $159.75 \pm 16.23$ & $171.63 \pm 13.12$ & 0.10 & 0.351 \\
Episodes duration (min) & $0.17 \pm 0.01$ & $0.16 \pm 0.01$ & 0.86 & 0.416 \\
Slow Wave Sleep & & & & \\
Total duration (min) & $67.67 \pm 4.64$ & $78.26 \pm 3.16 *$ & 3.68 & 0.008 \\
Number of episodes & $110.25 \pm 7.01$ & $120.00 \pm 5.18$ & 1.22 & 0.262 \\
Episodes duration (min) & $0.62 \pm 0.04$ & $0.66 \pm 0.03$ & 0.78 & 0.461 \\
Intermediate stage & & & & \\
Total duration (min) & $4.83 \pm 1.53$ & $5.38 \pm 1.08$ & 0.63 & 0.550 \\
Number of episodes & $15.00 \pm 3.24$ & $15.62 \pm 4.11$ & 0.22 & 0.822 \\
Episodes duration (min) & $0.31 \pm 0.03$ & $0.38 \pm 0.04$ & 1.69 & 0.135 \\
REM Sleep & & & & \\
Total duration (min) & $8.14 \pm 1.22$ & $11.94 \pm 1.19 *$ & 2.57 & 0.037 \\
Number of episodes & $7.75 \pm 1.61$ & $8.87 \pm 2.18$ & 0.59 & 0.575 \\
Episodes duration (min) & $1.35 \pm 0.30$ & $1.71 \pm 0.25$ & 1.33 & 0.225 \\
Latency REM (min) & $86.43 \pm 15.53$ & $65.33 \pm 7.38$ & 1.95 & 0.091 \\
Latency NREM (min) & $14.40 \pm 3.86$ & $9.73 \pm 0.99$ & 1.18 & 0.276 \\
\hline
\end{tabular}

Data is presented as mean \pm standard error of eight rats. ${ }^{*}$ denote significant difference compared to control values, using Student paired test. 
bioRxiv preprint doi: https://doi.org/10.1101/2021.05.06.442961 : this version posted May 7, 2021. The copyright holder for this preprint (which was not certified by peer review) is the author/funder, who has granted bioRxiv a license to display the preprint in perpetuity. It is made available under aCC-BY-NC-ND 4.0 International license.

Table 3. Effects of microinjection of HCRT-1 into mPOA on maternal behavior parameters during 4hour sessions.

\begin{tabular}{|c|c|c|c|c|c|c|}
\hline & \multirow[t]{2}{*}{ Vehicle } & \multirow[t]{2}{*}{ HCRT $_{100}$} & \multirow[t]{2}{*}{ HCRT $_{200}$} & \multicolumn{2}{|c|}{ ANOVA } & \multirow{2}{*}{$\begin{array}{c}\text { Tukey } \\
\mathrm{P}\end{array}$} \\
\hline & & & & $\mathbf{F}$ & $\mathbf{P}$ & \\
\hline \multicolumn{7}{|l|}{ Latency to (min): } \\
\hline Reunion litter & $8.50 \pm 4.11$ & $14.20 \pm 5.00$ & $8.75 \pm 4.05$ & 0.62 & 0.549 & \\
\hline Nursing & $8.69 \pm 1.29$ & $12.10 \pm 3.92$ & $8.74 \pm 1.40$ & 0.54 & 0.593 & \\
\hline \multicolumn{7}{|l|}{ Duration (min): } \\
\hline Nursing total & $171.52 \pm 6.99$ & $162.46 \pm 7.61$ & $154.43 \pm 12.37$ & 1.70 & 0.214 & \\
\hline Nursing Episodes & $12.44 \pm 1.25$ & $10.50 \pm 0.78$ & $11.29 \pm 1.61$ & 0.78 & 0.476 & \\
\hline \multicolumn{7}{|l|}{ Number of: } \\
\hline Nursing episodes & $15.11 \pm 1.31$ & $15.78 \pm 0.70$ & $15.56 \pm 1.58$ & 0.07 & 0.928 & \\
\hline Milk ejections & $21 \pm 2.09$ & $19.67 \pm 2.06$ & $16.67 \pm 1.29$ & 2.41 & 0.121 & \\
\hline Litter weight gain (\%) & $7.08 \pm 0.72$ & $4.77 \pm 0.49 *$ & $5.21 \pm 0.57$ & 4.16 & 0.035 & 0.038 \\
\hline
\end{tabular}

Data is presented as mean \pm SEM of nine rats. * denote significant difference compared to control values, using one-way repeated measures ANOVA followed by Tukey test.

Table 4. Effects of microinjection of DORA into MPOA on maternal behavior parameters during 4-hour sessions.

\begin{tabular}{lcccc}
\hline & DMSO & DORA & t-test & P \\
\hline Latency to $(\mathrm{min}):$ & & & & \\
$\quad$ Reunion litter & $1.56 \pm 0.09$ & $9.75 \pm 5.24$ & 1.55 & 0.172 \\
$\quad$ Nursing & $7.71 \pm 1.46$ & $6.12 \pm 0.72$ & 0.87 & 0.418 \\
Duration $(\mathrm{min})$ : & & & & \\
$\quad$ Nursing total & $121.38 \pm 12.67$ & $154.15 \pm 6.85^{*}$ & 4.07 & 0.007 \\
$\quad$ Nursing Episodes & $10.01 \pm 0.78$ & $12.67 \pm 2.05$ & 0.10 & 0.356 \\
Number of: & & & & \\
$\quad$ Nursing episodes & $12.14 \pm 0.86$ & $14 \pm 2.12$ & 1,30 & 0,239 \\
$\quad$ Milk ejections & $17 \pm 2.31$ & $27.14 \pm 3.39^{*}$ & 4.33 & 0.005 \\
Litter weight gain (\%) & $4.50 \pm 0.57$ & $5.32 \pm 0.50$ & 2.09 & 0.071 \\
\hline
\end{tabular}

Data is presented as mean \pm standard error of seven rats, * denote significant difference between groups, using Student paired test. 

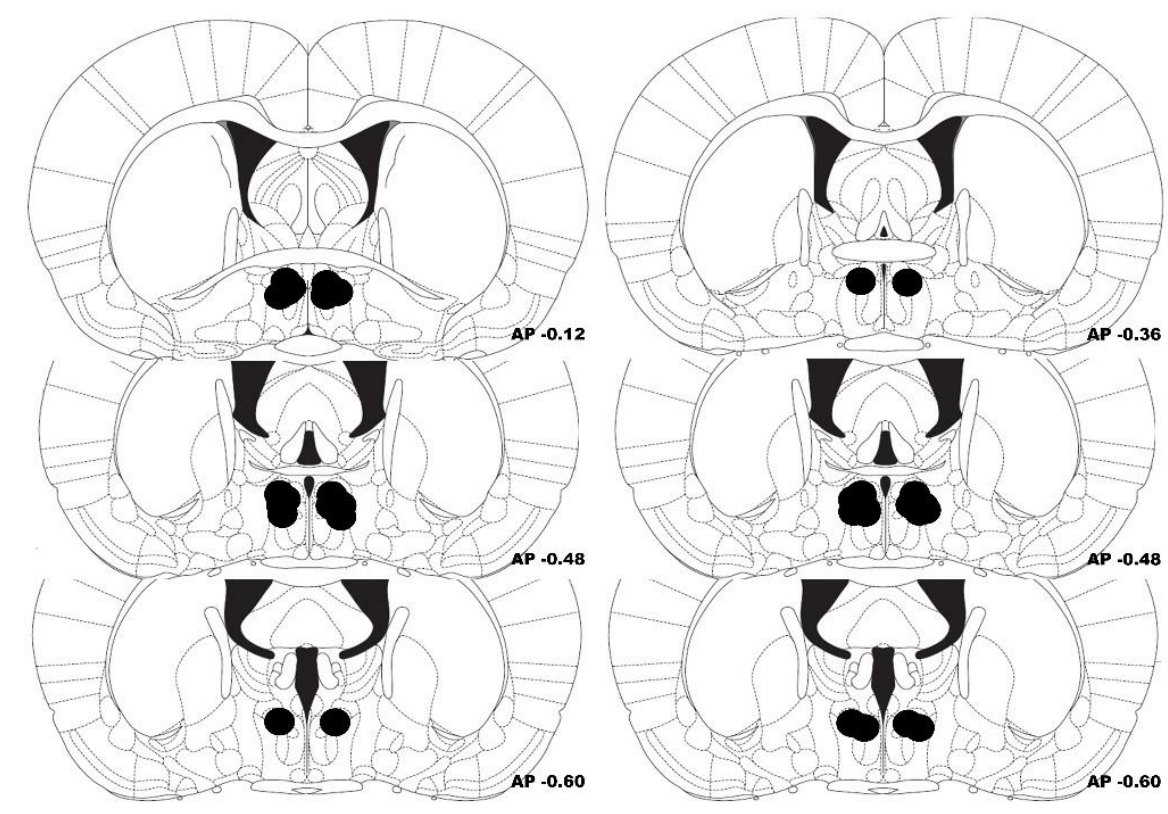

Figure 1. Microinjections sites. Schematic representations of coronal sections at the level of mPOA. Black circles indicate the microinjection sites of the HCRT-1 (left) and DORA group (right); bottom numbers indicate distance from Bregma. Plates were taken from the atlas of (Paxinos and Watson, 2005). 
A

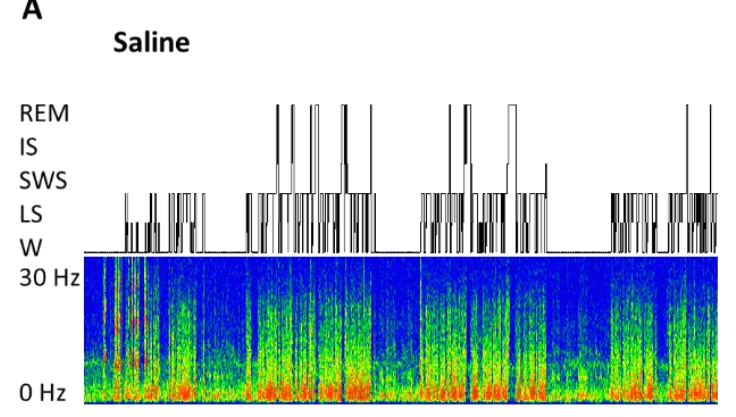

HCRT $_{200}$

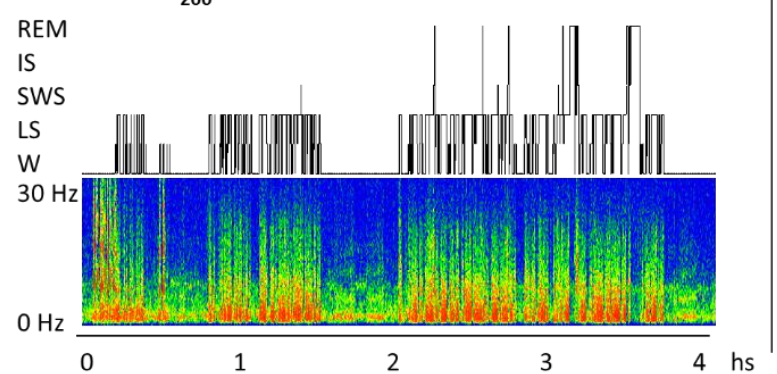

B

DMSO

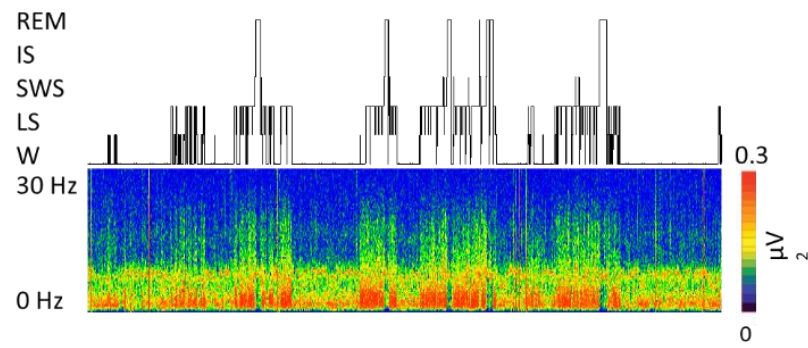

DORA

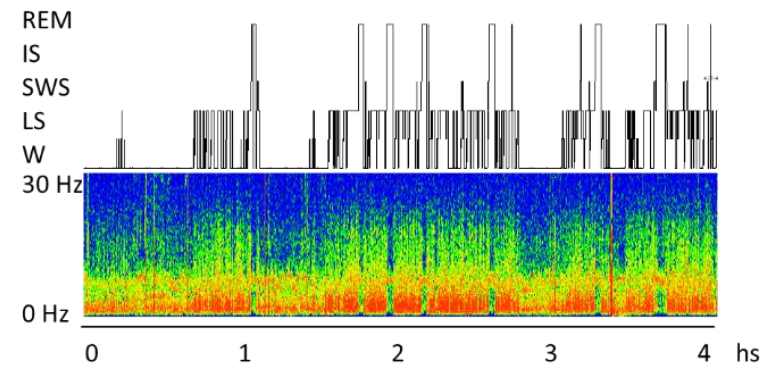

Figure 2. Hypnograms and spectrograms $(1-30 \mathrm{~Hz})$ from the prefrontal cortical recordings of a representative animal are shown after saline and $\mathrm{HCRT}_{200}(\mathrm{~A})$, and DMSO and DORA (B) local administration. W, wakefulness; LS, light sleep; SWS, slow wave sleep; IS, intermediate stage and REM, rapid eyes movements sleep. 

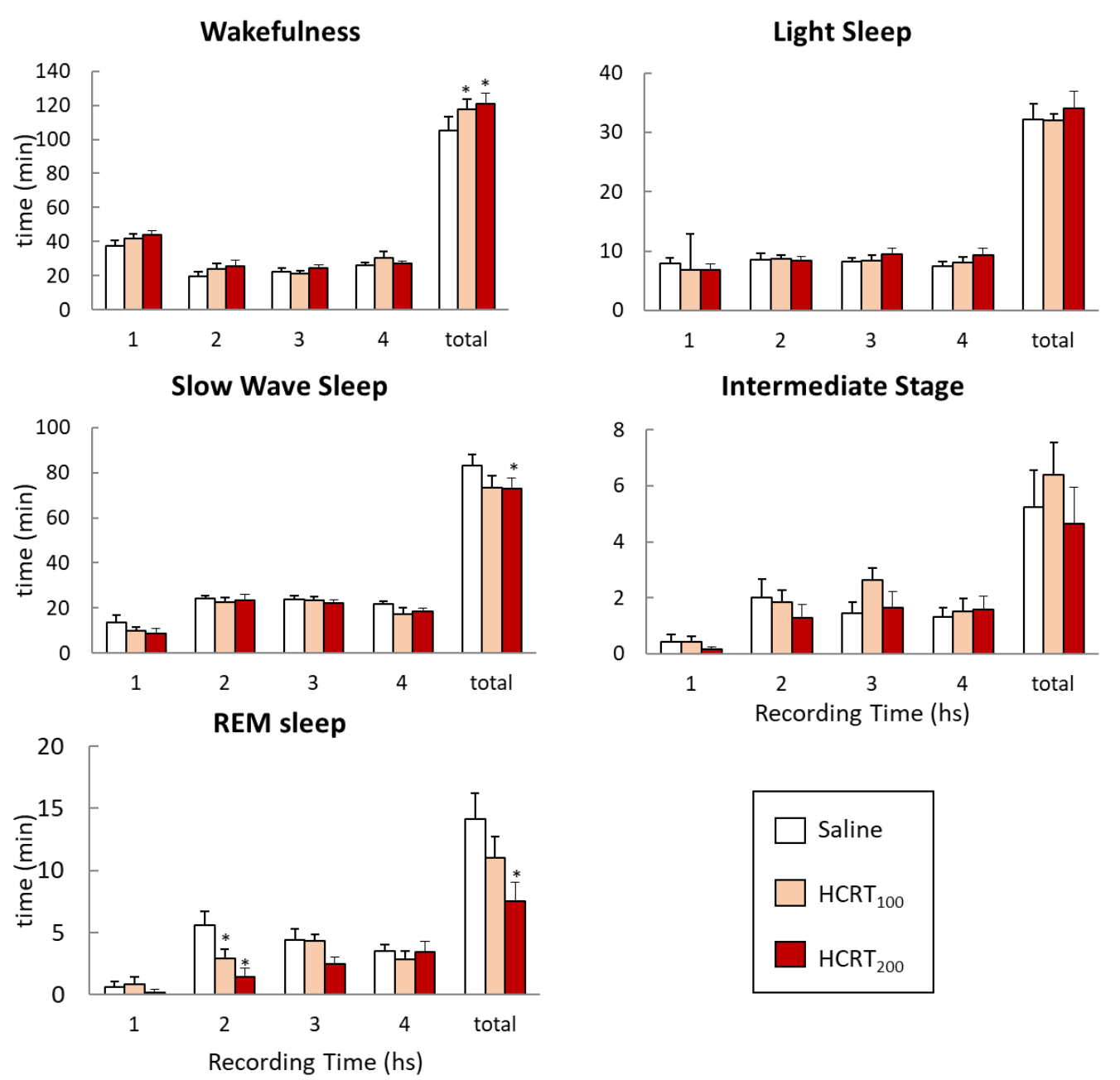

Figure 3. Effect of HCRT-1 microinjection into MPOA on sleep and wakefulness. The charts show the mean time ( \pm SEM) spent in wakefulness, light sleep, slow wave sleep, intermediate stage and REM sleep after local administration of saline, $\mathrm{HCRT}_{100}$ and $\mathrm{HCRT}_{200}$ during each hour and the total recording time. Group differences were determined by one-way repeated measures ANOVA followed by Tukey as post hoc; asterisks $(*)$ indicates significant differences compared to control values. 


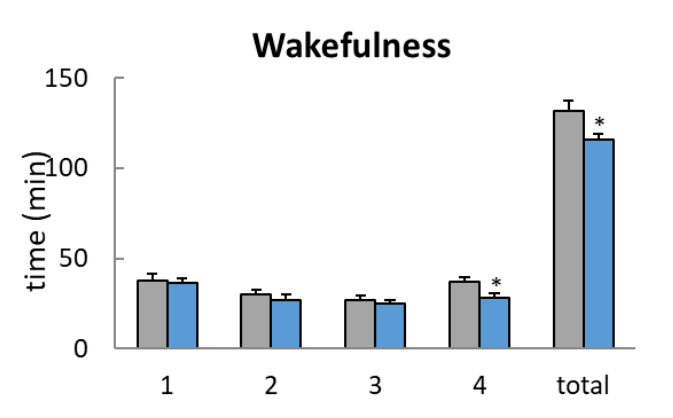

Slow Wave Sleep

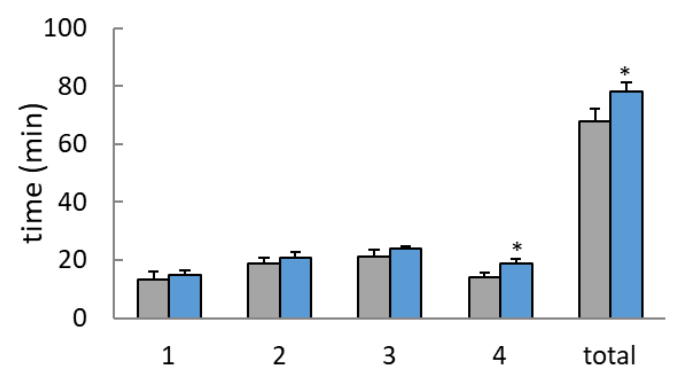

REM Sleep

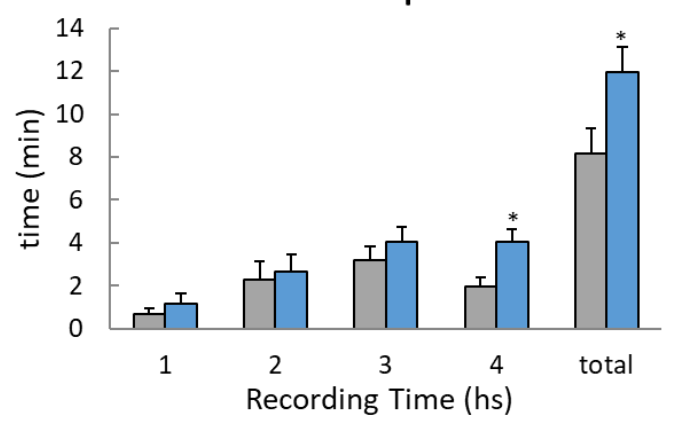

Light Sleep

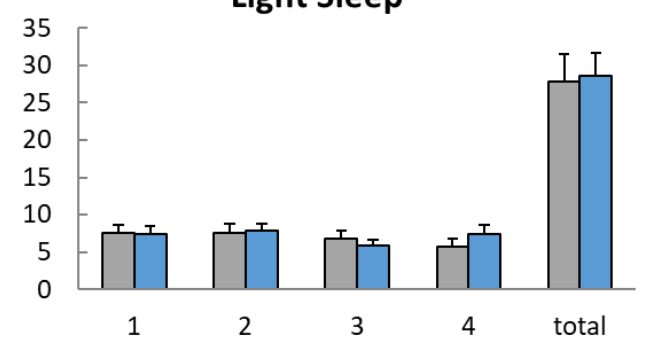

Intermediate Stage

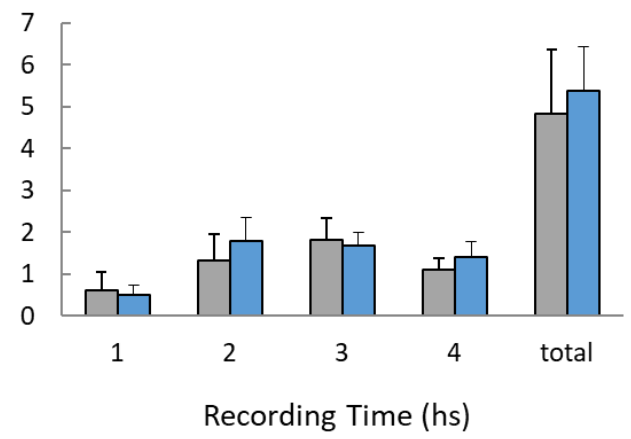

DMSO DORA

Figure 4. Effect of DORA microinjection into MPOA on sleep and wakefulness. The charts show the mean time spent in wakefulness, light sleep, slow wave sleep, intermediate stage and REM sleep after local administration of vehicle (DSMO 10\%) and DORA $5 \mathrm{mM}$ during each hour and the total recording time. Group differences were determined by paired Student test; * indicates significant differences compared to control values. 

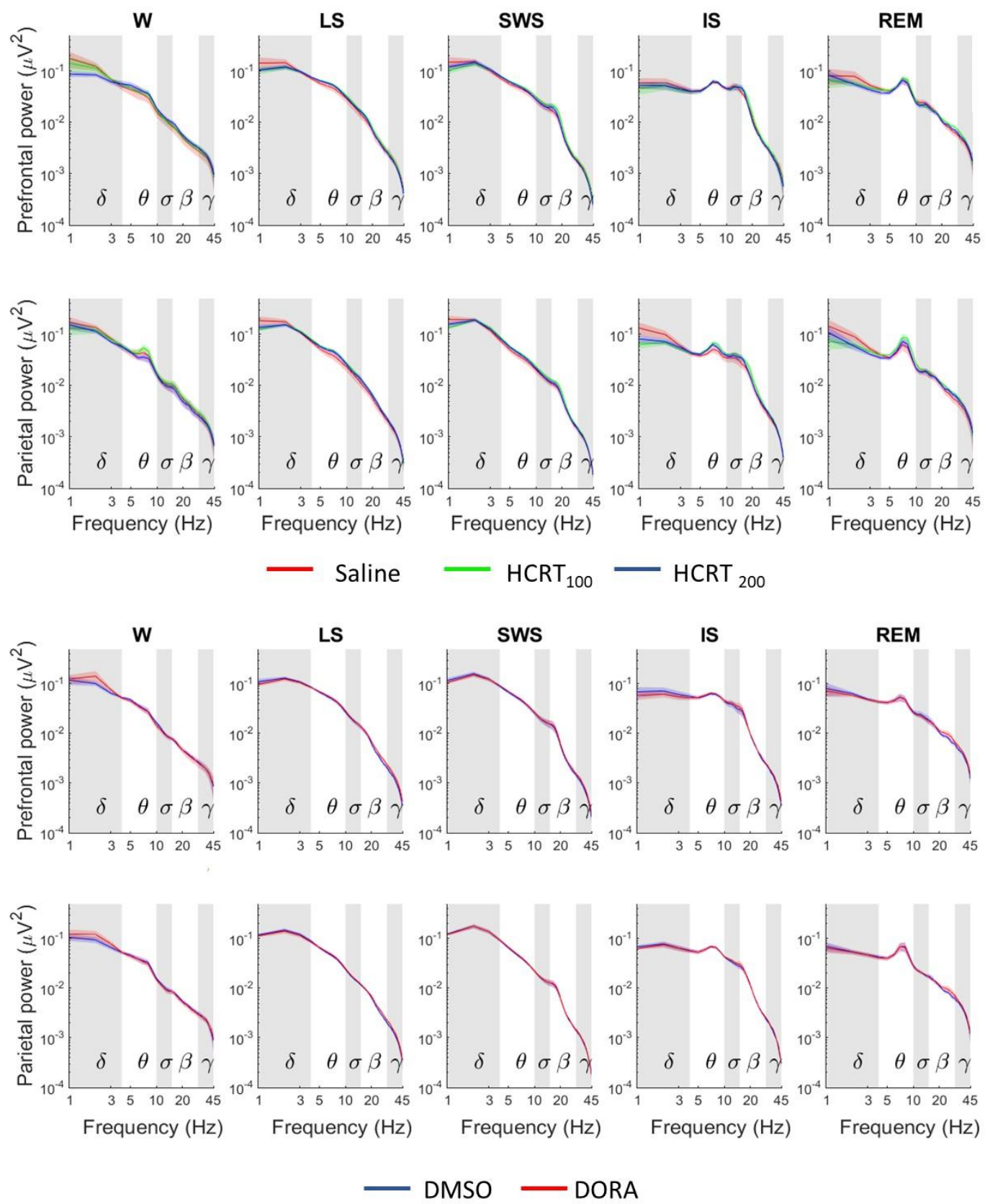

Figure 5. The graphs plot spectral power changes in the prefrontal and parietal cortex during every sleep state for frequencies between 1 and $30 \mathrm{~Hz}$ for HCRT-1 (top) and DORA (bottom) groups. Traces represent mean values (thin, dark lines) \pm SEM (shaded area above and below the mean). Frequency ranges are indicated by alternating horizontal colored bands in the background of the graphs: Delta (1-4 Hz), Theta $(4-10 \mathrm{~Hz})$, Sigma $(10-15 \mathrm{~Hz})$, Beta $(15-30 \mathrm{~Hz})$ and Gamma $(30-45 \mathrm{~Hz})$. For HCRT-1 Friedman test for multiple comparisons was employed for statistical comparison of spectral power in each frequency with control. Wilcoxon signed-rank test was used for DORA group. W, wakefulness; LS, light sleep; SWS, slow wave sleep; IS, intermediate stage and REM, rapid eyes movements sleep. 

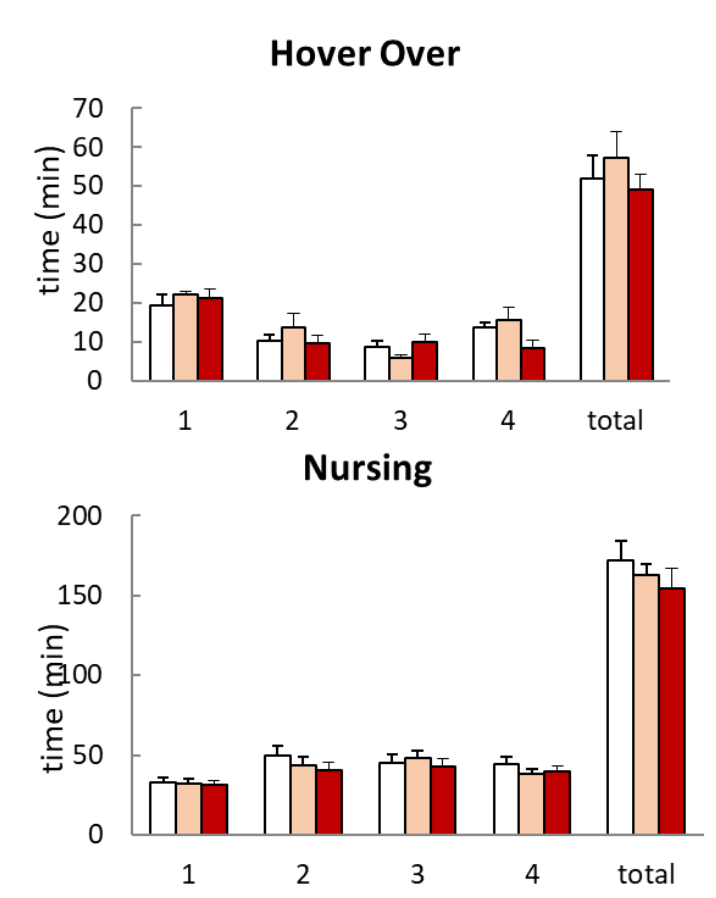

Away from the pups

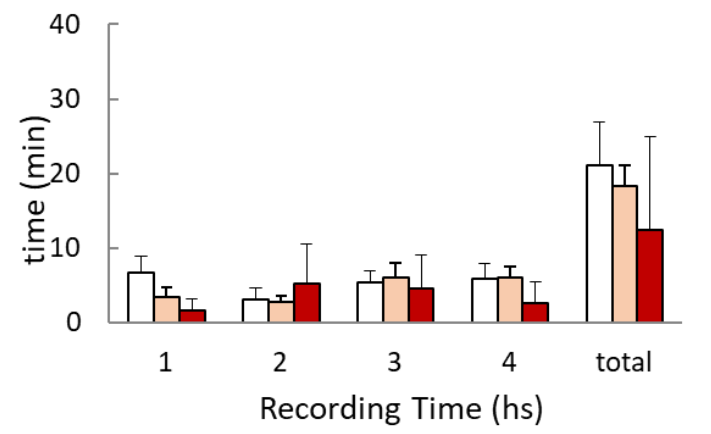

Saline
HCRT $_{100}$

$\mathrm{HCRT}_{200}$
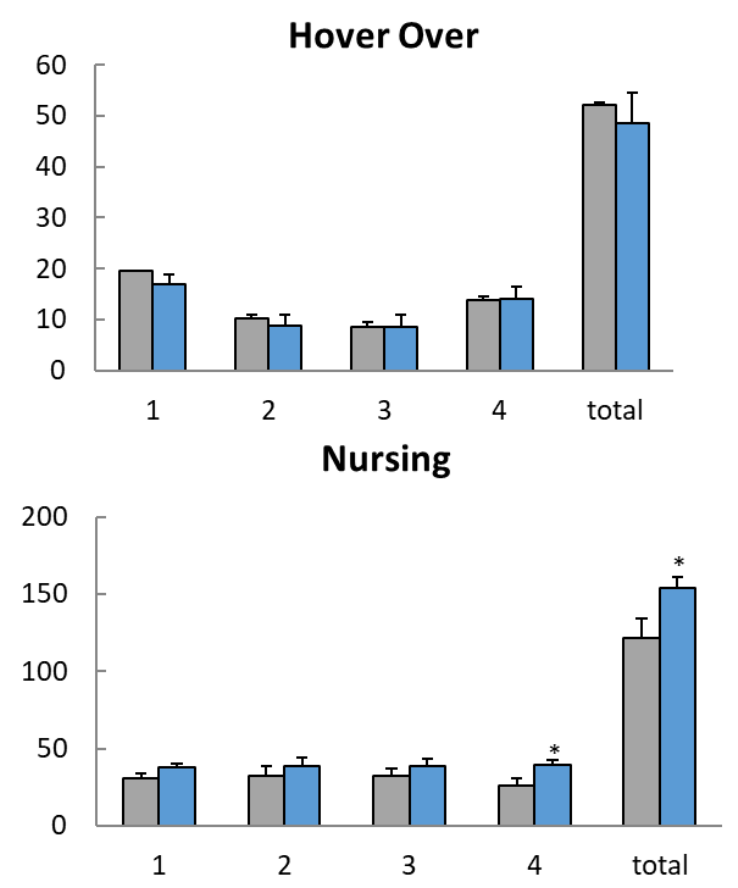

Away from the pups

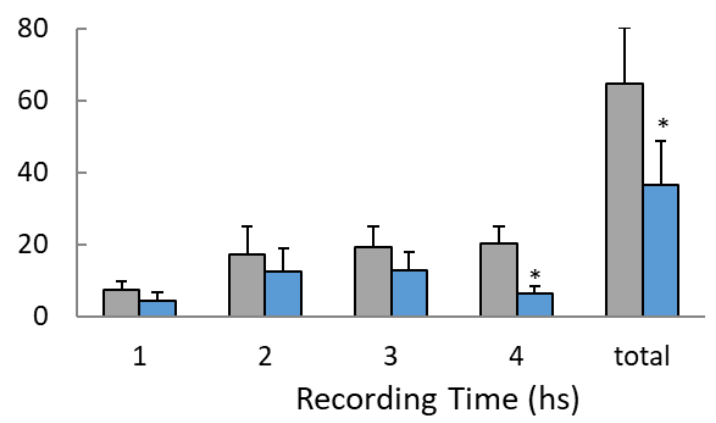

$\square$ DMSO $\square$ DORA

Figure 6. Effect of HCRT-1 and DORA microinjection into mPOA on maternal behaviors. The charts show the mean time spent in hover over, nursing, and away from the pups after local administration of saline, $\mathrm{HCRT}_{100}$ and $\mathrm{HCRT}_{200}$ (on the left), and DMSO and DORA (on the right), during each hour and the total recording time. Group differences were determined by one-way repeated measures ANOVA followed by Tukey in HCRT-1 groups, and Student paired test in DORA group; * indicates significant differences compared to control values. 


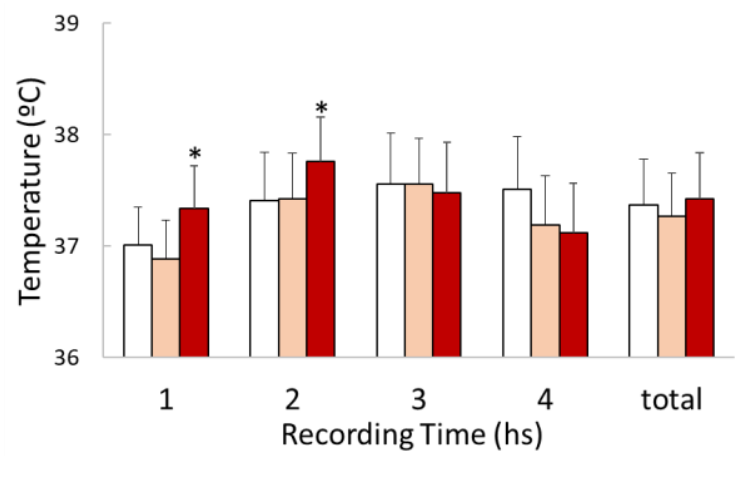

$\square$ Saline $\square$ HCRT $_{100} \quad \square$ HCRT $_{200}$

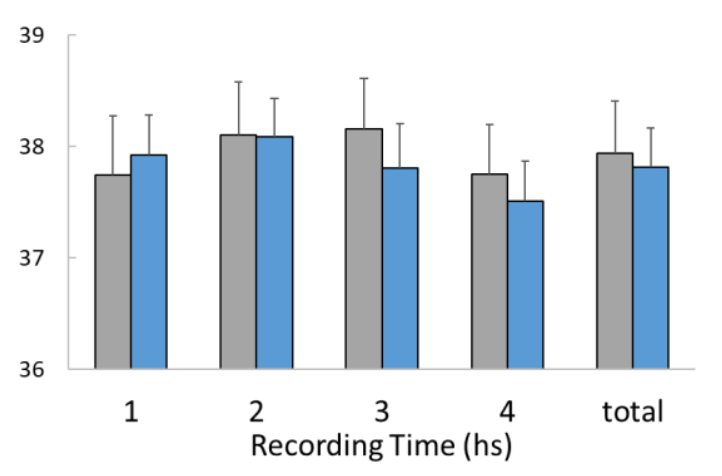

$\square$ DMSO $\square$ DORA

Figure 7. Effect of HCRT-1 and DORA microinjection into MPOA on body temperature. The charts show the average \pm SEM body temperature after local administration of saline, $\mathrm{HCRT}_{100}$ and $\mathrm{HCRT}_{200}$ (on the left), and DMSO and DORA (on the right), during each hour and in the total recording time. Group differences were determined by one-way repeated measures ANOVA followed by Tukey in HCRT-1 groups, and Student paired test in DORA group. * indicates significant differences compared to control values. 